\title{
Systematic review of health-related quality of life models
}

Tamilyn Bakas*, Susan M McLennon, Janet S Carpenter, Janice M Buelow, Julie L Otte, Kathleen M Hanna, Marsha L Ellett, Kimberly A Hadler and Janet L Welch

\begin{abstract}
Background: A systematic literature review was conducted to (a) identify the most frequently used health-related quality of life (HRQOL) models and (b) critique those models.

Methods: Online search engines were queried using pre-determined inclusion and exclusion criteria. We reviewed titles, abstracts, and then full-text articles for their relevance to this review. Then the most commonly used models were identified, reviewed in tables, and critiqued using published criteria.

Results: Of 1,602 titles identified, 100 articles from 21 countries met the inclusion criteria. The most frequently used HRQOL models were: Wilson and Cleary (16\%), Ferrans and colleagues (4\%), or World Health Organization (WHO) (5\%). Ferrans and colleagues' model was a revision of Wilson and Cleary's model and appeared to have the greatest potential to guide future HRQOL research and practice.

Conclusions: Recommendations are for researchers to use one of the three common HRQOL models unless there are compelling and clearly delineated reasons for creating new models. Disease-specific models can be derived from one of the three commonly used HRQOL models. We recommend Ferrans and colleagues' model because they added individual and environmental characteristics to the popular Wilson and Cleary model to better explain HRQOL. Using a common HRQOL model across studies will promote a coherent body of evidence that will more quickly advance the science in the area of HRQOL.
\end{abstract}

Keywords: Health-related quality of life, Conceptual models, Theories, Frameworks

\section{Introduction}

Health-related quality of life (HRQOL) has been identified as a goal for all people across all life stages by leading health organizations [1-3]. HRQOL, that is, quality of life relative to one's health or disease status, is a concern of policymakers, researchers, and health care practitioners [4]. Especially important is the need to align HRQOL research priorities with the needs and values of patients and their families. Because of the multidimensional aspects of HRQOL, and the varied use of this term across many different health and disease conditions, researchers have used a variety of HRQOL models to guide their research. A conceptual model is a schematic representation of a theory that acts as a heuristic device to provide a better understanding of a phenomenon (e.g., HRQOL) by

\footnotetext{
* Correspondence: tbakas@iupui.edu

Indiana University School of Nursing, 1111 Middle Drive, Indianapolis, IN, 46202, USA
}

depicting interrelationships among concepts [5]. The term conceptual model has been used interchangeably as "conceptual framework, theoretical model, or theoretically based conceptual model [6]."

There are many HRQOL models applied across different health and illness conditions, across the lifespan, and among individuals, their families, and communities. HRQOL is commonly conceived as dynamic, subjective, and multidimensional, and the dimensions often include physical, social, psychological, and spiritual factors [7]. However, the specific dimensions are labeled differently by different authors [7]. For example, these broad dimensions subsume more specific dimensions such as emotions, cognitive function, economic status, and intelligence [8], and they may incorporate friends and family [9]. While the theoretical underpinnings of HRQOL may be consistent across models, variations in terminology for analogous concepts make comparison across studies very difficult. 
Differing conceptualizations of HRQOL limit the ability to have a coherent body of evidence to guide further HRQOL research and practice. Common HRQOL models provide essential structure to the conceptualization of HRQOL using common language that can be shared across studies. Identification and evaluation of common HRQOL models can help guide research and practice toward promoting or attaining optimum HRQOL for populations of interest. Thus, the purposes of this paper were to (a) identify the most frequently used HRQOL models found in the literature over the past ten years and (b) review and critique the most commonly used models using established criteria by Bredow [10]. Although Bredow's [10] criteria were developed to critique middlerange theories in nursing research, they represent a comprehensive approach to theory analysis for review and critique of HRQOL models [10]. The overall goal was to determine the relevance of HRQOL models to research and practice aimed at improving HRQOL.

\section{Methods}

Several search engines were used to locate relevant articles. Initially, PubMed, MEDLINE, CINAHL, and PsychINFO were searched using the keywords quality of life, health-related quality of life, conceptual framework, conceptual model, and theory. Both quality of life and health-related quality of life were searched because these terms have been used interchangeably in the literature.

We limited our search to English language articles published between January 1, 1999 and August 31, 2010. The inclusion criteria were published articles pertaining to HRQOL models that had been used to guide (a) literature reviews, (b) instrument development studies, (c) descriptive or correlational studies, (d) intervention studies, or (e) practice. Articles in which research findings were used to derive HRQOL models were also included. We did not limit our search to specific populations (e.g., children, adolescents, adults, older adults) because we wanted a broad representation of the use of HRQOL models. Exclusion criteria were articles that did not pertain to humans, were non-English, or involved studies and information published only as dissertations, abstracts, editorials, or clinical opinion. Relevant articles were identified from the literature search using a three-step process. In the first step, authors working in pairs reviewed the article titles based on inclusion/exclusion criteria. In cases in which there was a lack of consensus between the two reviewers, a third reviewer was sought, consistent with methods outlined by the Joanna Briggs Institute [11]. In the second step, titles that met the criteria were further evaluated. Authors, again working in pairs, reviewed abstracts and reached agreement about whether the abstracts met inclusion/exclusion criteria. In the third step, the identified articles were obtained and evaluated by the same pairs of authors. Full text articles were reviewed and again were included only if the pairs agreed the article met the criteria.

The paired authors then extracted and consolidated pertinent information from the articles into a review table. Column variables in the table were: author and date, country of origin, purpose, methods, design, and model. Each row represented a unique article. All authors engaged in group discussion to reach consensus on articles to be included in the review and to determine the format in which to present review findings. After reviewing articles, the most commonly used HRQOL models were identified, fulfilling the first purpose of this review. For purpose two, each of the most commonly used HRQOL models was critiqued by the author pairs using established criteria by Bredow [10]. After considering several alternatives, we chose Bredow because he incorporated the most comprehensive criteria for evaluating theories, frameworks, and models [10]. Although these criteria are used to evaluate middle range theories in nursing research, they are also useful in evaluating quality of life theories [10]. A description of Bredow's [10] criteria appears in the first column of Table 1, and is summarized below.

Bredow's [10] criteria for evaluating theories were organized around two major areas: internal and external criticism. Internal criticism involves a judgment about the internal components of the theory, whereas external criticism involves a judgment about the match between the theory and context of its use. When evaluating internal criticism, the evaluator assesses the adequacy (thoroughness in addressing topic), clarity (clearness of statements), consistency (congruency in semantics, etc.), logical development (support from evidence), and level of theory development. To make judgments about external criticism, the evaluator assesses the complexity (number of concepts/variables, from parsimonious to complex), discrimination (uniqueness), reality convergence (relevant assumptions), pragmatism (ability to use in the real world), scope (narrow to broad use for practice), significance (impact of theory), and utility (ability to produce hypotheses). Critique information for each of the commonly used models was summarized in a table after consensus had been reached by two (or sometimes three) authors.

\section{Results}

The disposition of the search results is shown in Figure 1 as a PRISMA flow diagram [14]. Searching the three databases with the selected keywords yielded a total of 1,602 records. Author review excluded 50 records because they 
Table 1 Critique of three most commonly used HRQOL models

\begin{tabular}{|c|c|c|c|}
\hline $\begin{array}{l}\text { Criteria and } \\
\text { Description } \\
\text { (Bredow, [10]) }\end{array}$ & $\begin{array}{c}\text { Wilson \& Cleary Model of HRQOL } \\
\text { [12] }\end{array}$ & $\begin{array}{l}\text { Ferrans et al. Revised Wilson and } \\
\text { Cleary Model of HRQOL [13] }\end{array}$ & $\begin{array}{c}\text { World Health Organization } \\
\text { International Classification of } \\
\text { Functioning Disability and Health } \\
\text { (WHO ICF) [3] }\end{array}$ \\
\hline
\end{tabular}

\section{Internal criticism}

\section{Adequacy}

Addresses a defined

area

- Completeness

- Need for refinement - Refinement for specific practice

- Complete overall conceptualization of HRQOL from biomedical and social science perspectives

- Gaps

- Gaps include management of therapeutic regimens and selfmanagement situations needed.

Clarity

- Main concepts well-defined, although individual and environmental characteristics not explained.

Explicit components

- Explicit proposition that dominant relationships exist with the potential for reciprocal relationships.

- Concepts

(components) defined

- Strength of the relationships of each component is unclear and with each additional relationship the complexity increases.

- Explicit propositions - Other relationships were implied. (Relationships)

- Explicit assumptions (Beliefs)

\section{- Explicit assumption that} understanding relationships among these domains will lead to the design of optimally effective clinical interventions.
- Expanded Wilson \& Cleary's model to better explicate individual and environmental factors

- Gaps still include management of therapeutic regimens and selfmanagement

- Refinement for specific practice situations needed.

- Main concepts well-defined, including individual and environmental characteristics.

- Explicit proposition that dominant relationships exist with the potential for reciprocal relationships.

- Propositions were added with individual and environmental characteristics.

- Nonmedical factors removed; described as part of individual and environmental characteristics.

- Explicit assumption that understanding relationships among these domains will lead to the design of optimally effective clinical interventions.
- Complete overall conceptualization of health from biomedical and social science perspectives

- Gaps include determinants of health, management of risk factors, and selfmanagement

- Refinement for specific practice situations needed.

- Main concepts well-defined, with the exception of overlap between activities and participation.

- Explicit propositions exist with reciprocal relationships that can be used to map the constructs and domains.

- Explicit assumption that model provides a multipurpose classification and can serve as a unified and standard language for health care workers, researchers, policy-makers, and the public.

- Another explicit assumption is that model can be used to help plan interventions for functional goals and health, worldwide.

\section{Consistency}

Consistency

- Concepts

Congruency

- Assumptions (beliefs)

- Propositions (relationships)

- Concepts consistently defined.

- Assumptions were congruent

- The figure depicts dominant directional relationships whereas the text mentions reciprocal and other non-depicted relationships.

Logical
development

Based on previous work Evidence supports

\section{- Emerged based on research from} biomedical and social sciences.

- Relationships depicted don't always hold true, research evidence supports lack of relationships in some instances (e.g., biological vs. symptoms)
- Concepts consistently defined.

- Assumptions were congruent

- Propositions were congruent.

- Revision of Wilson \& Cleary

- Emerged based on empirical evidence and the need for further clarity.
- Concepts consistently defined.

- Assumptions were congruent

- Propositions were congruent.

- Integration of medical and social models for a biopsychosocial approach.

- Evolved over time from the WHO ICIDH model in 1980 to the WHO ICF in 2001, with the WHO ICF-CY for children and adolescents added in 2007. 
Table 1 Critique of three most commonly used HRQOL models (Continued)

\section{Level of development}

Level of abstraction (grand, middle range,

or practice)

\author{
- Middle range but global \\ Middle range but global \\ Middle range but global
}

\begin{tabular}{|c|c|c|c|}
\hline \multicolumn{4}{|l|}{ External criticism } \\
\hline \multicolumn{4}{|l|}{ Complexity } \\
\hline - Number of concepts & $\begin{array}{l}\text { - } 5 \text { main abstract concepts } \\
\text { (biological/physiological, symptom } \\
\text { status, functional status, general } \\
\text { health, quality of life) }\end{array}$ & $\begin{array}{l}\text { - } 5 \text { main abstract concepts with } \\
\text { further development of the } \\
\text { individual and environmental factors. }\end{array}$ & $\begin{array}{l}\text { - } 6 \text { main abstract concepts (body } \\
\text { functions, body structures, activity, } \\
\text { participation, environmental factors, and } \\
\text { personal factors). }\end{array}$ \\
\hline - Parsimony & $\begin{array}{l}\text { - Parsimonious because used only } 5 \\
\text { main concepts to explain abstract } \\
\text { HRQOL. }\end{array}$ & $\begin{array}{l}\text { - Parsimonious because used only } 7 \\
\text { main concepts to explain abstract } \\
\text { HRQOL. }\end{array}$ & $\begin{array}{l}\text { - Parsimonious because used only } 6 \\
\text { main concepts to explain abstract health } \\
\text { and health-related states. }\end{array}$ \\
\hline - Complexity & $\begin{array}{l}\text { - Overall model is complex with } \\
\text { multiple relationships }\end{array}$ & $\begin{array}{l}\text { - Overall model is complex with } \\
\text { multiple relationships }\end{array}$ & $\begin{array}{l}\text { - Overall model is complex with multiple } \\
\text { relationships }\end{array}$ \\
\hline Discrimination & $\begin{array}{l}\text { - First HRQOL model to combine } \\
\text { biomedical with social science }\end{array}$ & $\begin{array}{l}\text { - Revised Wilson and Cleary's HRQOL } \\
\text { model }\end{array}$ & $\begin{array}{l}\text { - Belongs to a family of WHO } \\
\text { Classifications, with the WHO ICF being } \\
\text { specific to functioning and disability. }\end{array}$ \\
\hline \multirow{3}{*}{$\begin{array}{l}\text { Unique theory of } \\
\text { HRQOL with clear } \\
\text { boundaries }\end{array}$} & - Unique to HRQOL & - Unique to HRQOL & - Not unique to HRQOL. \\
\hline & $\begin{array}{l}\text { - Boundaries are purposefully not } \\
\text { clear as two theories are combined } \\
\text { and the relationships between } \\
\text { concepts are additive. }\end{array}$ & $\begin{array}{l}\text { - Clear boundaries and limited to } \\
\text { HRQOL of individuals. }\end{array}$ & $\begin{array}{l}\text { - Clear boundaries addressing health and } \\
\text { health-related domains. }\end{array}$ \\
\hline & $\begin{array}{l}\text { - Hypotheses generation may help to } \\
\text { clarify boundaries. }\end{array}$ & & $\begin{array}{l}\text { - Does not cover non-health related } \\
\text { circumstances. }\end{array}$ \\
\hline Reality convergence & $\begin{array}{l}\text { - Moving from cellular level to } \\
\text { quality of life in model seems more } \\
\text { realistic than traditional biomedical } \\
\text { model by itself. }\end{array}$ & $\begin{array}{l}\text { - Realism added with the } \\
\text { incorporation of nonmedical factors } \\
\text { into individual and environmental } \\
\text { factors. }\end{array}$ & $\begin{array}{l}\text { - Assumptions seem true, realistic, and } \\
\text { consistent. }\end{array}$ \\
\hline $\begin{array}{l}\text { - Assumptions "real } \\
\text { world" }\end{array}$ & $\begin{array}{l}\text { - "Makes sense" for real world } \\
\text { application. }\end{array}$ & $\begin{array}{l}\text { - "Makes sense" for real world } \\
\text { application. }\end{array}$ & $\begin{array}{l}\text { - "Makes sense" for real world } \\
\text { application. }\end{array}$ \\
\hline $\begin{array}{l}\text { - Theory/model } \\
\text { "makes sense" }\end{array}$ & $\begin{array}{l}\text { - Assumptions are difficult to } \\
\text { actualize }\end{array}$ & - Assumptions more realistic & \\
\hline Pragmatic & $\begin{array}{l}\text { Guided literature applied to real } \\
\text { world settings: }\end{array}$ & $\begin{array}{l}\text { Guided literature applied to real } \\
\text { world settings: }\end{array}$ & $\begin{array}{l}\text { Guided literature applied to real world } \\
\text { settings: }\end{array}$ \\
\hline \multirow{10}{*}{$\begin{array}{l}\text { Operationalized in } \\
\text { real-life settings }\end{array}$} & - 3 literature reviews, & - 2 literature reviews & - 3 literature reviews \\
\hline & - 4 descriptive, & - 1 instrument development & - 2 instrument development \\
\hline & & Model testing in entirety not done & Model testing in entirety not done \\
\hline & - 6 correlational, & $\begin{array}{l}\text { - Overall, generic and situation- } \\
\text { specific measures exist }\end{array}$ & $\begin{array}{l}\text { - Overall, generic and situation-specific } \\
\text { measures exist }\end{array}$ \\
\hline & - 1 randomized trial, & $\begin{array}{l}\text { - Response shift is a concern for } \\
\text { general health and quality of life } \\
\text { components }\end{array}$ & - Response shift may also be a concern. \\
\hline & - 1 qualitative, & & \\
\hline & - 1 mixed methods & & \\
\hline & $\begin{array}{l}\text { - } 1 \text { model revision (Ferrans) Model } \\
\text { testing in entirety rarely done }\end{array}$ & & \\
\hline & $\begin{array}{l}\text { - Overall, generic and situation- } \\
\text { specific measures exist }\end{array}$ & & \\
\hline & $\begin{array}{l}\text { - Response shift is a concern for } \\
\text { general health and quality of life } \\
\text { components }\end{array}$ & & \\
\hline
\end{tabular}


Table 1 Critique of three most commonly used HRQOL models (Continued)

\begin{tabular}{|c|c|}
\hline Scope & \\
\hline $\begin{array}{l}\text { - breadth of theory/ } \\
\text { model }\end{array}$ & $\begin{array}{l}\text { - Broad model to explain complex } \\
\text { nature of HRQOL }\end{array}$ \\
\hline $\begin{array}{l}\text { - applies across ages } \\
\text { (lifespan), health and } \\
\text { disease conditions, } \\
\text { cultures, } \\
\text { socioeconomics, and } \\
\text { individuals/families/ }\end{array}$ & $\begin{array}{l}\text { - Could apply to individuals of all } \\
\text { ages, life spans, health and disease } \\
\text { conditions, and perhaps cultures } \\
\text { depending on their orientation to } \\
\text { the meaning of quality of life and } \\
\text { general health. }\end{array}$ \\
\hline & $\begin{array}{l}\text { - May not apply to those who are } \\
\text { unable to define their own general } \\
\text { health or quality of life (e.g., infants, } \\
\text { comatose), or those who have very } \\
\text { limited functioning. }\end{array}$ \\
\hline & $\begin{array}{l}\text { - Primarily applies to individuals, less } \\
\text { to families and communities. }\end{array}$ \\
\hline Significance & - Most widely cited HRQOL model \\
\hline $\begin{array}{l}\text { - Potential impact on } \\
\text { practice }\end{array}$ & $\begin{array}{l}\text { - Guides HRQOL assessment toward } \\
\text { a more comprehensive approach to } \\
\text { improving HRQOLPotential for } \\
\text { intervention research but limited } \\
\text { evidence exists to date. }\end{array}$ \\
\hline $\begin{array}{l}\text { - Hypotheses lead to } \\
\text { assessment or } \\
\text { interventions }\end{array}$ & $\begin{array}{l}\text { - Because of the complexity of the } \\
\text { model and lack of testing of the full } \\
\text { model, supporting interventions } \\
\text { would be difficult. }\end{array}$ \\
\hline
\end{tabular}

Scope

- breadth of theory/

- applies across ages (lifespan), health and disease conditions, cultures, viduals/families/ conditions, and perhaps cultures depending on their orientation to the meaning of quality of life and

- May not apply to those who are unable to define their own genera

- Primarily applies to individuals, less to families and communities. model, supporting interventions would be difficult.
- Further broadens Wilson and Cleary's scope by expanding on individual and environmental factors - Emerging citations for Revised
HRQOL model

- Guides HRQOL assessment toward a more comprehensive approach to improving HRQOL

- Potential for intervention research but limited evidence exists to date.
- Broad model to explain health and health-related domains for all people.

- Could apply to individuals of all ages, life spans, health and disease conditions, and cultures across the world.

- WHO ICF-CY specifically covers infants, children, and adolescentzs.

- Focus is on individuals (with or without disabilities), families, communities, and populations.

\begin{tabular}{ll}
\hline Utility & Hypothesis generating for: \\
Hypothesis & - Clinicians for a broader view of \\
generating for & HRQOL than just biological factors \\
Clinicians, researchers, & and symptoms. \\
epidemiologists, &
\end{tabular}

- Researchers to guide measurement and intervention studies:
- Potentially relevant to epidemiologists if using global measures across populations (e.g., SF-36)
- More research evidence and emphasis on environmental factors needed to convince policymakers.

\section{Hypothesis generating for:}

- Clinicians for a broader view of HRQOL than just biological factors and symptoms.

- Expands focus of article (audience) from physicians (Wilson \& Cleary) to nurses and other health professionals (Ferrans). Model could be applied to any health care discipline.

- Researchers to guide measurement and intervention studies.

- Potentially relevant to epidemiologists if using global measures across populations (e.g. SF-36).

- More research evidence and emphasis on environmental factors needed to convince policymakers.
- Emerging citations for the use of the WHO ICF for hypothesis testing (mainly instrument development).

- As a clinical tool, can be used for needs assessments, matching treatments with conditions, and evaluating outcomes.

- As a research tool, can be used for measuring quality of life, outcomes, environmental factors, or other constructs.

- Potential for intervention research but limited evidence exists to date. More of a mapping and classification framework, rather than hypothesis generating.

Hypothesis generating for:

- Clinicians for needs assessments, matching treatments with conditions, vocational assessment, and rehabilitation and outcome evaluation

- Researchers to guide development of measures for outcomes, quality of life, or environmental factors

- Epidemiologists to collect and record data for populations and management information systems

- Policymakers to plan social security, compensation systems, and policies.

- Educators to design curriculums that emphasize awareness and social action.

- Although potential for hypothesis generation in these areas, there is currently limited evidence found in the HRQOL literature documenting these applications. 


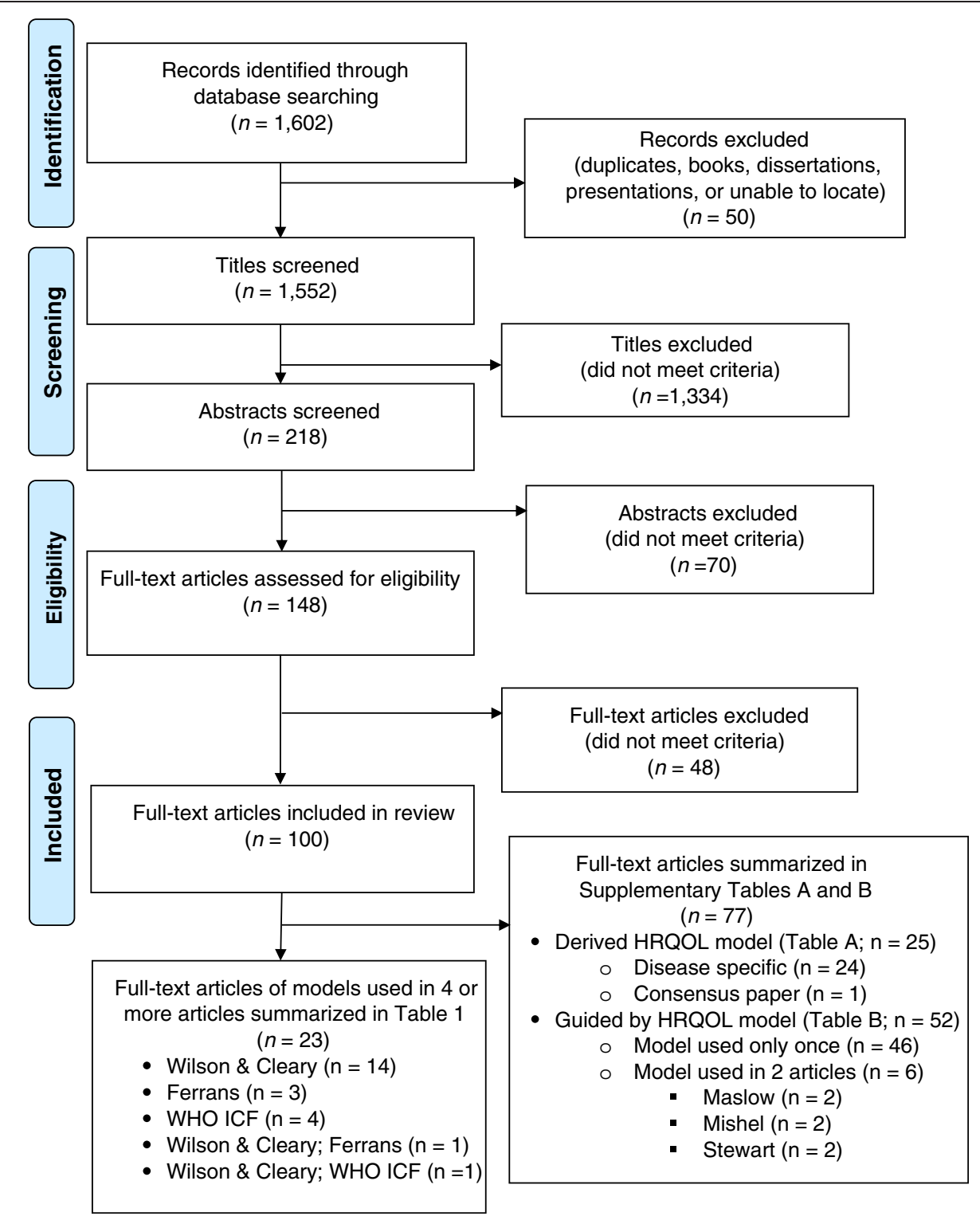

Figure 1 Literature search flow diagram.

were duplicates, books, dissertations, presentations, or could not be located. This left 1,552 titles to screen. Author pairs excluded 1,334 titles because they did not meet inclusion criteria. This left 218 abstracts to be screened, of which 70 did not meet inclusion criteria; 148 progressed to the full text assessment for eligibility. Of the 148 full text articles assessed, 48 were eliminated because a HRQOL model had not been derived from or used to guide the research, review, and/or findings. This process resulted in a total of 100 articles being included in this review (see Figure 1).

Of the 100 articles, 46 were quantitative. Of the remaining 54, 16 were qualitative research, 1 was mixed methods research, 15 involved instrument development,
20 were literature reviews, 1 described a model revision, and 1 was a consensus paper. The 46 quantitative studies were mainly descriptive studies $(n=31)$, with a few being correlational $(n=13)$, or randomized controlled trials $(n=2)$. Sample sizes ranged from 10 [15] to 69,031 participants [16]. The 100 articles came from 21 different countries including Australia $(n=4)$, Austria $(n=1)$, Brazil $(n=3)$, Canada $(n=12)$, China $(n=3)$, Finland $(n=1)$, Germany $(n=4)$, India $(n=1)$, Ireland $(n=1)$, Israel $(n=1)$, Italy $(n=2)$, Japan $(n=1)$, Netherlands $(n=7)$, Norway $(n=2)$, Spain $(n=3)$, Sweden $(n=2)$, Taiwan $(n=1)$, Thailand $(n=4)$, Ukraine $(n=1)$, United Kingdom $(n=10)$, and the United States $(n=49)$. Of these 100 articles, 9 involved more than one country. 


\section{Most frequently used HRQOL models}

Of the 100 articles, 57 used an existing HRQOL model as a guide and 25 derived a HRQOL model. Interestingly, 18 articles used an existing HRQOL model as an initial guide and then also derived a revised model based on the findings. Figure 1 shows that of the 100 full-text articles included in the review, 77 either derived a HRQOL model $(\mathrm{n}=25)$ or were guided by a HRQOL model that was used only once or twice $(n=52)$. There was little consensus among the models used, with each article essentially citing a different model. These 77 articles are summarized in Additional file 1: Tables SA and SB included as an appendix for this paper. Of the 25 articles that derived a HRQOL model, 24 were diseasespecific, and 1 was a consensus paper on HRQOL (Additional file 1: Table SA). The disease-specific models were classified as using a uniquely derived HRQOL model based on the findings. For example, Barr and Schumacher [17] identified six categories of HRQOL specific to individuals receiving medical nutrition therapy. Similarly, Klassen, Pusic, Scott, Klok, \& Cano [18] examined the impact of breast conditions and surgery to develop a quality of life framework specific to breast surgery patients. Because there was such a wide variation in disease states, HRQOL domains, and particular characteristics, findings could not be adequately synthesized. Of the 52 articles that were guided by a HRQOL model that was used only once $(\mathrm{n}=46)$ or twice $(n=6)$, only three HRQOL models were cited twice (Additional file 1: Table SB). Those used twice were Maslow's hierarchy of needs $(n=2)$, Mishel's Uncertainty in Illness Theory $(n=2)$, and Stewart's conceptual model of factors affecting dying patients and families $(\mathrm{n}=2)$ (See Additional file 1: Table SB for details).

As depicted at the bottom of Figure 1, there remained a total of 23 articles that cited the same model 4 or more times. As shown in Table 2 (and in Figure 1), the most common existing HRQOL models found in the literature were those by Wilson and Cleary [12] $(n=14)$, Ferrans and colleagues [13,19] $(n=3)$, and the World Health Organization (WHO) $[20,21](n=4)$. Two additional articles used a combination of two of these models. Ferrans et al. [13] used the Wilson and Cleary [12] model as a guide to derive a revised model of HRQOL [13]. Valderas and Alonso [22] used both Wilson and Cleary [12] and the WHO [20] models. Schematic diagrams for each of the three most common HRQOL models have been published in Wilson and Cleary [12], Ferrans and colleagues [13], and the World Health Organization [20,21], and are described in more detail in the results section. The largest group $(n=10)$ of the 23 articles in Table 2 reported observational studies (descriptive or correlational) and focused on patients with chronic illness, with sample sizes ranging from
61 [23] to 917 [24]. Literature reviews $(n=6)$ and instrument development studies $(n=3)$ were also found. Only one randomized controlled trial was found [25], along with one mixed-methods study [26], one qualitative study [27], and one article that described a model revision [13].

\section{Critical analysis of predominant HRQOL models}

Table 1 details the critique of the three most commonly used HRQOL models found in the literature over the past 10 years using criteria by Bredow [10]. Wilson and Cleary's [12] model of HRQOL combines two paradigms, biomedical and social science. Their model is a taxonomy that includes five major well-defined domains: biological, symptoms, function, general health perception, and overall HRQOL. However, the definitions for two other domains, individual and environmental characteristics, were not made explicit. Each domain is related to the others, and reciprocal relationships may exist. The authors suggest that environmental and individual factors are associated with outcomes, thus affecting total HRQOL.

Ferrans, Zerwic, Wilbur, and Larson [13] published a revision of Wilson and Cleary's [12] HRQOL model. The five major domains of the original model were retained. Ferrans and colleagues [13] made explicit the definitions for individual and environmental characteristics, and they simplified the depiction of the model by removing non-medical factors and labels on the arrows portraying the relationships in the figure. In addition, they contributed further theoretical background about the main concepts in the model [19] and provided examples of instruments to enhance measurement. According to Ferrans et al. [13], the model depicts dominant causal associations; however, reciprocal relationships are implied. An explicit assumption is that understanding relationships among these components will lead to the design of optimally effective clinical interventions. The revised conceptual model could be applied to any health care discipline.

The World Health Organization International Classification of Functioning, Disability, and Health (WHO ICF) is a model designed to provide a description of health and health states, while providing a unified and standard language that can be used across disciplines and cultures $[3,20,21]$. The WHO ICF has evolved over time from a focus on "consequences of disease" in 1980 to "components of health" in 2001 [20,21]. The more recently developed WHO ICF-CY covers infants, children, and adolescents [3]. The WHO has conceptualized HRQOL as an individual's perception of his or her health and health-related domains of well-being $[3,21,43]$. Health and health-related domains have been further conceptualized in terms of functioning within the WHO ICF model. The WHO ICF model includes components within two main parts. Part 1 focuses on functioning and 
Table 2 Subset of articles based on three most commonly used HRQOL models

\begin{tabular}{|c|c|c|c|c|c|}
\hline $\begin{array}{l}\text { Model used } \\
\text { [Reference] }\end{array}$ & $\begin{array}{l}\text { Authors [Reference] } \\
\text { Country }\end{array}$ & Purpose & Design & Sample & $\begin{array}{l}\text { Model } \\
\text { guided or } \\
\text { derived }\end{array}$ \\
\hline Wilson \& Cleary [12] & $\begin{array}{l}\text { Baker, Pankhurst, \& Robinson } \\
\text { [25] United Kingdom }\end{array}$ & $\begin{array}{l}\text { To test Wilson and Cleary's } \\
\text { conceptual model of the direct and } \\
\text { mediated pathways between clinical } \\
\text { and non-clinical variables in relation } \\
\text { to oral health-related quality of life } \\
\text { (OHRQOL). }\end{array}$ & $\begin{array}{l}\text { Randomized } \\
\text { Controlled } \\
\text { Trial }\end{array}$ & $\begin{array}{l}85 \text { patients with } \\
\text { xerostomia } \\
\text { attending outpatient } \\
\text { clinics }\end{array}$ & Guided \\
\hline Wilson \& Cleary [12] & $\begin{array}{l}\text { Cosby, Holzemer, Henry, \& } \\
\text { Portillo [28] United States }\end{array}$ & $\begin{array}{l}\text { To determine relationships among } \\
\text { anemia, neutropenia, and } \\
\text { thrombocytopenia and the five } \\
\text { dimensions of the Wilson and Cleary } \\
\text { model of HRQOL. }\end{array}$ & Correlational & $\begin{array}{l}146 \text { hospitalized } \\
\text { patients with AIDS }\end{array}$ & Guided \\
\hline Wilson \& Cleary [12] & $\begin{array}{l}\text { Frank, Auslander, \& } \\
\text { Weissgarten [29] Israel }\end{array}$ & $\begin{array}{l}\text { To examine quality of life among } \\
\text { patients undergoing different types } \\
\text { of treatment for end-stage renal } \\
\text { disease at different points of the } \\
\text { disease. }\end{array}$ & Descriptive & $\begin{array}{l}72 \text { patients with } \\
\text { end-stage renal } \\
\text { disease }\end{array}$ & Guided \\
\hline Wilson \& Cleary [12] & $\begin{array}{l}\text { Hofer, Benzer, Alber, } \\
\text { Ruttmann, Kopp, Schussler, } \\
\text { et al. [30] Austria, Ireland, } \\
\text { Germany }\end{array}$ & $\begin{array}{l}\text { To apply the Wilson and Cleary } \\
\text { model a priori to patients with } \\
\text { coronary artery disease. }\end{array}$ & Correlational & $\begin{array}{l}465 \text { patients with } \\
\text { coronary artery } \\
\text { disease }\end{array}$ & Guided \\
\hline Wilson \& Cleary [12] & $\begin{array}{l}\text { Janz, Janevic, Dodge, } \\
\text { Fingerlin, Schork, Mosca, } \\
\text { et al., [31] United States }\end{array}$ & $\begin{array}{l}\text { To describe the impact of clinical } \\
\text { and psychosocial factors on the } \\
\text { quality of life of older women with } \\
\text { heart disease. }\end{array}$ & Descriptive & $\begin{array}{l}570 \text { older women } \\
\text { with heart disease }\end{array}$ & Guided \\
\hline Wilson \& Cleary [12] & $\begin{array}{l}\text { Krethong, Jirapaet, Jitpanya, } \\
\text { \& Sloan [32] Thailand }\end{array}$ & $\begin{array}{l}\text { To examine causal relationships } \\
\text { among bio-physiological status, } \\
\text { symptoms, functional status, general } \\
\text { health perception, HRQOL, and social } \\
\text { support. }\end{array}$ & Correlational & $\begin{array}{l}422 \text { Thai patients } \\
\text { with heart failure }\end{array}$ & Guided \\
\hline Wilson \& Cleary [12] & $\begin{array}{l}\text { Mathias, Gao, Miller, Cella, } \\
\text { Snyder, Turner, et al. [27] } \\
\text { United States }\end{array}$ & $\begin{array}{l}\text { To develop a conceptual model to } \\
\text { describe the impact of immune } \\
\text { thrombocytopenic purpura on } \\
\text { HRQOL. }\end{array}$ & $\begin{array}{l}\text { Qualitative \& } \\
\text { Literature } \\
\text { Review }\end{array}$ & $\begin{array}{l}23 \text { patients with } \\
\text { immune } \\
\text { thrombocytopenic } \\
\text { purpura }\end{array}$ & $\begin{array}{l}\text { Guided } \\
\text { Derived }\end{array}$ \\
\hline Wilson \& Cleary [12] & $\begin{array}{l}\text { Mathisen, Andersen, Veenstra, } \\
\text { Wahl, Hanestad, \& Fosse [33] } \\
\text { Norway }\end{array}$ & $\begin{array}{l}\text { To determine whether reciprocal } \\
\text { relationships existed between quality } \\
\text { of life and health appraisal in those } \\
\text { with coronary artery bypass surgery. }\end{array}$ & Correlational & $\begin{array}{l}120 \text { patients with } \\
\text { coronary artery } \\
\text { bypass surgery }\end{array}$ & $\begin{array}{l}\text { Guided } \\
\text { Derived }\end{array}$ \\
\hline Wilson \& Cleary [12] & $\begin{array}{l}\text { Orfila, Ferrer, Lamarca, Tebe, } \\
\text { Domingo-Salvany, \& Alonso } \\
\text { [34] Spain }\end{array}$ & $\begin{array}{l}\text { To determine whether gender } \\
\text { differences in HRQOL among the } \\
\text { elderly are explained by differences } \\
\text { in performance-based functional } \\
\text { capacity and chronic conditions. }\end{array}$ & Descriptive & 544 elderly persons & $\begin{array}{l}\text { Guided } \\
\text { Derived }\end{array}$ \\
\hline Wilson \& Cleary [12] & $\begin{array}{l}\text { Penckofer Ferrans, Fink, } \\
\text { Barrett, \& Holm [23] United } \\
\text { States }\end{array}$ & $\begin{array}{l}\text { To determine effect of coronary } \\
\text { artery bypass Graft (CABG) surgery } \\
\text { on quality of life of women. }\end{array}$ & Descriptive & $\begin{array}{l}61 \text { women with } \\
\text { coronary artery } \\
\text { bypass Surgery }\end{array}$ & Guided \\
\hline Wilson \& Cleary [12] & Sousa [35] United States & $\begin{array}{l}\text { To describe a HRQOL model to } \\
\text { guide clinical practice. }\end{array}$ & $\begin{array}{l}\text { Literature } \\
\text { Review }\end{array}$ & NA & Guided \\
\hline Wilson \& Cleary [12] & $\begin{array}{l}\text { Sousa \& Kwok [24] United } \\
\text { States }\end{array}$ & $\begin{array}{l}\text { To validate Wilson \& Cleary's model } \\
\text { using structural equation modeling } \\
\text { in HIV+ patients. }\end{array}$ & Correlational & 917 HIV+ patients & Guided \\
\hline Wilson \& Cleary [12] & $\begin{array}{l}\text { Vidrine, Amick, Gritz, \& } \\
\text { Arduino [36] Israel }\end{array}$ & $\begin{array}{l}\text { To empirically assess a proximal- } \\
\text { distal framework for conceptualizing } \\
\text { HRQOL in individuals living with HIV/ } \\
\text { AIDS. An integrated model based on } \\
\text { Wilson and Cleary (2005) was used. }\end{array}$ & Correlational & $\begin{array}{l}348 \text { people with } \\
\text { HIV/AIDS }\end{array}$ & $\begin{array}{l}\text { Guided } \\
\text { Derived }\end{array}$ \\
\hline Wilson \& Cleary [12] & $\begin{array}{l}\text { Wettergren, Bjorkholm, } \\
\text { Axdorph, \& Langius-Eklof, } \\
\text { [26] Sweden }\end{array}$ & $\begin{array}{l}\text { To examine determinants of HRQOL } \\
\text { in long-term survivors of Hodgkin's } \\
\text { Disease. }\end{array}$ & $\begin{array}{l}\text { Mixed } \\
\text { Methods }\end{array}$ & $\begin{array}{l}121 \text { long-term } \\
\text { Hodgkin's lymphoma } \\
\text { survivors }+236 \\
\text { healthy controls }\end{array}$ & Guided \\
\hline
\end{tabular}


Table 2 Subset of articles based on three most commonly used HRQOL models (Continued)

\begin{tabular}{|c|c|c|c|c|c|}
\hline Ferrans et al. [13] & $\begin{array}{l}\text { Daggett, Bakas, \& Habermann } \\
\text { [37] United States }\end{array}$ & $\begin{array}{l}\text { To identify gaps in current } \\
\text { knowledge of HRQOL and traumatic } \\
\text { brain injury and apply findings to } \\
\text { developing recommendations for } \\
\text { future research with combat } \\
\text { veterans with traumatic brain injury. }\end{array}$ & $\begin{array}{l}\text { Literature } \\
\text { Review }\end{array}$ & N/A & Guided \\
\hline Ferrans \& Powers [19] & $\begin{array}{l}\text { Hill, Aldag, Hekel, Riner, \& } \\
\text { Bloomfield [38] United States }\end{array}$ & $\begin{array}{l}\text { To develop and test psychometric } \\
\text { properties of a maternal post-partum } \\
\text { quality of life measure. }\end{array}$ & $\begin{array}{l}\text { Instrument } \\
\text { Development }\end{array}$ & $\begin{array}{l}184 \text { post partum } \\
\text { mothers }\end{array}$ & Guided \\
\hline Ferrans \& Powers [19] & $\begin{array}{l}\text { Petchprapai \& Winkelman } \\
\text { [39] Thailand United States }\end{array}$ & $\begin{array}{l}\text { To analyze the literature related to } \\
\text { the clinical, theoretical, and empirical } \\
\text { determinates of mild traumatic brain } \\
\text { injury. }\end{array}$ & $\begin{array}{l}\text { Literature } \\
\text { Review }\end{array}$ & $\mathrm{N} / \mathrm{A}$ & Guided \\
\hline $\begin{array}{l}\text { World Health } \\
\text { Organization [20] }\end{array}$ & $\begin{array}{l}\text { Fischer, LaRocca, Miller, Ritvo, } \\
\text { Andrews, \& Paty [40] Canada } \\
\text { \& United States }\end{array}$ & $\begin{array}{l}\text { To (1) review recent efforts to assess } \\
\text { the broader impact of MS on quality } \\
\text { of life; (2) describe the development } \\
\text { of the MS Quality of Life Inventory } \\
\text { (MSQLI); (3) discuss issues to } \\
\text { consider in selecting an MS quality } \\
\text { of life instrument. }\end{array}$ & $\begin{array}{l}\text { Instrument } \\
\text { Development }\end{array}$ & $\begin{array}{l}15 \mathrm{MS} \text { patients in } \\
\text { pilot test, } 300 \mathrm{MS} \\
\text { patients in field test }\end{array}$ & Guided \\
\hline $\begin{array}{l}\text { World Health } \\
\text { Organization [21] }\end{array}$ & $\begin{array}{l}\text { Hays, Hahn, \& Marshall [41] } \\
\text { United States }\end{array}$ & $\begin{array}{l}\text { To examine different conceptual } \\
\text { models of HRQOL and examine } \\
\text { implications of these perspectives for } \\
\text { measurement of HRQOL in persons } \\
\text { with disabilities. }\end{array}$ & $\begin{array}{l}\text { Literature } \\
\text { Review }\end{array}$ & $\mathrm{N} / \mathrm{A}$ & Guided \\
\hline $\begin{array}{l}\text { World Health } \\
\text { Organization [20] }\end{array}$ & John [15] Germany & $\begin{array}{l}\text { To explore the dimensional structure } \\
\text { of OHRQOL using experts' opinions } \\
\text { using a conceptual model of oral } \\
\text { health. }\end{array}$ & $\begin{array}{l}\text { Instrument } \\
\text { Development }\end{array}$ & $\begin{array}{l}10 \text { dentists \& } 4 \\
\text { psychologists }\end{array}$ & Guided \\
\hline $\begin{array}{l}\text { World Health } \\
\text { Organization [20] }\end{array}$ & $\begin{array}{l}\text { Post, deWitte, \& Schrijvers } \\
\text { [42] Netherlands }\end{array}$ & $\begin{array}{l}\text { To extend the World Health } \\
\text { Organization international } \\
\text { classification of impairments, } \\
\text { disabilities, and handicaps in } \\
\text { rehabilitation. }\end{array}$ & $\begin{array}{l}\text { Literature } \\
\text { Review }\end{array}$ & N/A & $\begin{array}{l}\text { Guided } \\
\text { Derived }\end{array}$ \\
\hline $\begin{array}{l}\text { Wilson \& Cleary [12]; } \\
\text { Ferrans et al., [13] }\end{array}$ & $\begin{array}{l}\text { Ferrans, Zerwic, Wilbur, \& } \\
\text { Larson [13] United States }\end{array}$ & $\begin{array}{l}\text { To revise the Wilson and Cleary } \\
\text { model of HRQOL. }\end{array}$ & $\begin{array}{l}\text { Model } \\
\text { Revision }\end{array}$ & N/A & $\begin{array}{l}\text { Guided } \\
\text { Derived }\end{array}$ \\
\hline $\begin{array}{l}\text { Wilson \& Cleary [12]; } \\
\text { World Health } \\
\text { Organization [20] }\end{array}$ & $\begin{array}{l}\text { Valderas \& Alonso [22] United } \\
\text { Kingdom Spain }\end{array}$ & $\begin{array}{l}\text { To develop a classification system for } \\
\text { patient-reported outcome measures } \\
\text { based on Wilson \& Cleary's HRQOL } \\
\text { conceptual model and the World } \\
\text { Health Organization International } \\
\text { Classification of Functioning. }\end{array}$ & $\begin{array}{l}\text { Literature } \\
\text { Review }\end{array}$ & NA & $\begin{array}{l}\text { Guided } \\
\text { Derived }\end{array}$ \\
\hline
\end{tabular}

disability (body functioning and structures, activities, and participation), whereas Part 2 addresses contextual factors (environmental and personal). The main concepts are well-defined overall, with explicit propositions and assumptions. However, unlike the models by Wilson and Cleary [12] and Ferrans and colleagues [13], the WHO ICF is not specific to HRQOL. Cieza and Stuki [43] assert that the WHO ICF categories under functioning can serve as the basis for the operationalization of HRQOL but are not the only potential application of the WHO ICF. For example, Miller and colleagues [44] used the WHO ICF as a framework to organize a comprehensive overview of nursing and interdisciplinary care of the stroke patient. The WHO ICF serves more as a mapping and classification framework than as a guide for hypothesis generation in the area of HRQOL.
Critique of the internal components of the HRQOL models using the Bredow criteria [10] indicated many similarities and some differences. All were fairly complete in the descriptions and definitions of HRQOL, with some gaps in the influence of management of therapeutic regimens and self-management on quality of life. Most existing models focus on the influence of symptoms rather than on management related to the condition. For example, for those with diabetes, both symptoms (such as hypoglycemia) and management (such as frequent checking of glucose levels) are important influential factors for HRQOL. Within the WHO ICF model [3], there was some definitional overlap between activities and participation. The Ferrans et al. [13] model was more complete and clear than that of Wilson and Cleary [12] because of the revisions and because of better definitions 
for individual and environmental factors. The relationships among the concepts were less clear in the Wilson and Cleary model [12], whereas the Ferrans et al. model [13] added clarity. Both the Wilson and Cleary [12] and Ferrans et al. [13] models implied potential reciprocity. In contrast, the WHO ICF [3] was explicit with the depiction of causal and reciprocal relationships.

There were greater variations among the three models when critiquing model fit with operational application. The models were similarly parsimonious, yet the complexities of multiple relationships were described. They made sense for use in real-world settings and have been used to guide research and practice. A major difference is that the Wilson and Cleary [12] and Ferrans et al. [13] models specifically explain HRQOL, whereas the WHO ICF model [3] describes health related to functioning and disability. In addition, though the Wilson and Cleary [12] and Ferrans et al. [13] models were primarily intended for application to individuals, the WHO ICF model [3] could be used to explain the health of individuals, families, communities, populations, and cultures. With the former, adaptations may be needed for use with families, communities, and individuals unable to report their own HRQOL, such as infants and young children and those with cognitive impairment. Empirical evidence for use of the models for intervention research is limited. However, the Ferrans et al. [13] model and the WHO ICF model [3] have robust potential for guiding the design of interventions that could be tested and applied in practice settings. The WHO ICF may be more applicable to practice situations for needs assessments, matching treatments with conditions, and evaluating outcomes because it is primarily a classification and mapping system. All three models were at a similar level of development emerging from the two paradigms of biomedical and social sciences.

\section{Discussion and recommendations}

There are two important findings from this review. First, there has been little consistency in HRQOL models within the literature of the past 10 years. Approximately three-fourths of the articles reviewed used an existing HRQOL model as a guide; however, most of these applied a variety of different models, rather than using a common model found in the literature such as the Wilson and Cleary model [12]. Thus, there were wide variations in terminology for analogous HRQOL concepts, making cross-study comparisons virtually impossible. This seriously limits the ability to have a coherent body of evidence to guide further HRQOL research and practice. Second, the most commonly used models were based on work by Wilson and Cleary [12], the revised model by Ferrans and colleagues [13,19], and the WHO [3,20,21]. A majority of the researchers using these models could be doing so because of an absence of better alternatives. However, based on our findings, we recommend that authors consider the advantages of using one of the three commonly used global models in research to more quickly advance the science in the area of HRQOL. Our findings show that Wilson and Cleary [12], as well as the revisions of Wilson and Cleary's model proposed by Ferrans et al. [13], together are the most frequently referenced in the HRQOL literature, representing nearly a quarter of all of the articles reviewed. Ferrans and colleagues' [13] model provides clear conceptual and operational definitions, and it also clarifies relationships among concepts to guide research and practice. The WHO ICF model [3] may be useful in specific HRQOL studies; however, it has more potential for application to studies of an epidemiological, sociological, or educational nature.

There are a great many models in the HRQOL literature that have not been adequately tested or refined. Cross-comparisons across diseases could be done if authors had at least used a global HRQOL model as a starting point. In fact, many single-use models included the same concepts as the three global HRQOL models but labeled them differently. In the future, when a common global HRQOL model is not used, authors should clearly delineate why a context- or disease-specific model is preferred. Increasing the consistency in models used across studies would help increase our understanding of this important concept.

Of the 23 articles citing the three most common HRQOL models, most articles were descriptive, correlational, or literature reviews. Importantly, future HRQOL research should involve comparisons of intervention outcomes. Only one randomized controlled trial was found that used the most commonly cited Wilson and Cleary [12] model [25]. Although disease-specific or situationspecific models may be better for testing interventions, the global models should still be useful as a template and a jumping-off point for adaptations to specific contexts. In addition, using an existing model can advance the state of the science of HRQOL by contributing new information about the applicability of the selected model to research and practice, thus leading to model refinement such as the revised model proposed by Ferrans and colleagues [13]. This underscores the need to start with the best available HRQOL models and build upon them, rather than creating new models.

\section{Limitations}

Our search strategies were limited to selected databases (PubMed, MEDLINE, CINAHL, and PsychINFO) and keywords (e.g., quality of life, health-related quality of life, conceptual framework, conceptual model, and theory). Given that standard keywords were used within each 
search engine, any article indexed by that search engine would have been captured; however, follow up manual searches and review of reference lists might have revealed additional citations. The search strategies were specifically designed to capture articles that were guided by or derived HRQOL models that were further analyzed in detail by the reviewers. All reviewers were doctorallyprepared and a research librarian assisted with the searches. Because the aim of our paper was to identify the most frequently-used HRQOL models found in the literature over the past 10 years, a complete synthesis of disease-specific models was not undertaken. Future work to analyze uniquely derived disease-specific HRQOL models may provide unique HRQOL domains that might further inform the three more commonly used HRQOL models. For example, Klassen et al. [18] qualitatively derived a HRQOL model for women who had undergone breast surgery. Their model consisted of six themes (satisfaction with breasts, satisfaction with process of care, satisfaction with overall outcome, psychosocial well-being, sexual well-being, and physical well-being). The satisfaction with process of care theme further informs both Ferrans and colleagues' model [13] and the WHO ICF $[3,20,21]$ as an important characteristic of the environment. Sexual well-being could further inform the functional status domains in all three models. Identifying domains that are unique to disease-specific models, or particular characteristics such as feedback or recursive patterns to address dynamic changes in HRQOL with time, may further inform or strengthen the rationale for using the three existing HRQOL models.

\section{Conclusion}

In summary, based on this systematic review of the literature, Ferrans et al., [13] revision of Wilson and Cleary's [12] model appears to have the greatest potential to guide HRQOL research and practice. We recommend Ferrans and colleagues' [13] model because they added individual and environmental characteristics to the popular Wilson and Cleary [12] model to better explain HRQOL. Although the WHO ICF model has been considered a model of HRQOL, it is more of a mapping and classification framework than a guide for hypothesis generation in the area of HRQOL. Use of one model, such as Ferrans et al. [13] revised HRQOL model, will provide more opportunities for testing and refinement of the model and more evidence about which relationships among HRQOL concepts are common to different populations. Finally, and maybe most importantly, using one model will help in comparing HRQOL across studies and populations, contribute to the development of more intervention studies, and more quickly advance the science in the area of HRQOL.

\section{Additional file}

Additional file 1: Supplementary tables and references for the 100 Full-Text Articles reviewed for the manuscript entitled, "Systematic Review of Health-Related Quality of Life Models."

\section{Abbreviations}

HRQOL: Health-related Quality of Life; QOL: Quality of Life; WHO: World Health Organization; WHO ICF: World Health Organization International Classification of Functioning, Disability, and Health.

\section{Competing interests}

The authors declare that they have no competing interests.

\section{Authors' contributions}

TB provided overall leadership and contributed to the conception and design, participated in the review and critique process, drafted sections of the manuscript, and revised it critically for intellectual content. SMM, JSC, $J M B, J L O, K M H, M L E, \& J L W$ contributed to the conception and design, participated in the review and critique process, drafted sections of the manuscript, and revised it critically for intellectual content. $\mathrm{KAH}$ acquired articles for review, abstracted findings to tables, contributed to analysis and interpretation, provided reference management, and drafted sections of the manuscript. All authors read and approved the final manuscript.

\section{Acknowledgements}

Funding for this study was provided by Indiana University School of Nursing Research Investment Funds and the Center for Enhancing Quality of Life in Chronic Illness. The authors thank Phyllis Dexter, RN, PhD, Assistant Scientist and Editor, Indiana University School of Nursing Center for Nursing Research, for her editorial assistance. The authors also wish to thank Randi L. Stocker, Research Librarian at Indiana University Purdue University at Indianapolis, for her assistance with literature searches.

Received: 6 June 2012 Accepted: 7 November 2012

Published: 16 November 2012

\section{References}

1. Centers for Disease Control and Prevention (CDC: Measuring Healthy Days. Atlanta, Georgia: CDC; 2000.

2. Healthy People: Topics and Objectives Index - Healthy People. HealthyPeople. gov; 2011. http://healthypeople.gov/2020/topicsobjectives2020/default.aspx.

3. World Health Organization: International Classification of Functioning, disability, and Health: Children and Youth Version: ICF-CY. Geneva: World Health Organization; 2007.

4. Till JE, Osoba D, Pater JL, Young JR: Research on health-related quality of life: dissemination into practical applications. Qual Life Res 1994, 3(4):279-283.

5. Walker LO, Avant KC: Strategies for theory construction in nursing. 4th edition. New York: Prentice Hall; 2005

6. Vallerand $\mathrm{AH}$, Payne JK: Theories and conceptual models to guide quality of life related research. In Quality of life: from nursing and patient perspectives. 2nd edition. Edited by King CR, Hinds PS, Sudbury MA. Sudbury, MA, USA: Jones \& Bartlett Publishers; 2003:45-54.

7. Haas BK: A multidisciplinary concept analysis of quality of life. West J Nurs Res 1999, 21(6):728-742.

8. Mandzuk L, McMillan D: A concept analysis of quality of life. J Orthop Nurs 2005, 9(1):12-18. doi:JAN4277[pii]10.1111/j.1365-2648.2007.04277.x.

9. Taylor RM, Gibson F, Franck LS: A concept analysis of health-related quality of life in young people with chronic illness. J Clin Nurs 2008, 17(14):823-1833. doi:JCN2379[pii]10.1111/j.1365-2702.2008.02379.x.

10. Bredow TS: Analysis, evaluation, and selection of a middle range nursing theory. In Middle range theories: Application to nursing research. 2nd edition. Edited by Peterson SJ, Bredow TS. Philadelphia: Lippincott Williams \& Wilkins; 2009:46-60.

11. Joanna Briggs Institute: Joanna Briggs Institute Reviewer's Manual. 2008th edition. South Adelaide, Australia: The Joanna Briggs Institute; 2008.

12. Wilson IB, Cleary PD: Linking clinical variables with health-related quality of life: A Conceptual model of patient outcomes. JAMA 1995, 273(1):59-65. 
13. Ferrans CE, Zerwic JJ, Wilbur JE, Larson JL: Conceptual model of healthrelated quality of life. J Nurs Scholarsh 2005, 37(4):336-342.

14. Moher D, Liberati A, Tetzlaff J, Altman DG: The PRISMA Group: Preferred Reporting Items for Systematic Reviews and Meta-Analyses: The PRISMA Statement. PLoS Med 2009, 6(6):e1000097. doi:10.1371/journal. pmed1000097.

15. John MT: Exploring dimensions of oral health-related quality of life using experts' opinions. Qual Life Res 2007, 16(4):697-704. doi:10.1007/s11136006-9150-8.

16. Simon $A E$, Chan KS, Forrest CB: Assessment of children's health-related quality of life in the United States with a multidimensional index. Pediatrics 2008, 121(1):e118-126. doi:peds.2007-0480[pii]10.1542/peds.2007-0480.

17. Barr J, Schumacher G: Using focus groups to determine what constitutes quality of life in clients receiving medical nutrition therapy: first steps in the development of a nutrition quality-of-life survey. J Am Diet Assoc 2003, 103(7):844-851. doi:10.1053/jada.2003.50170S0002822303003857[pii].

18. Klassen AF, Pusic AL, Scott A, Klok J, Cano SJ: Satisfaction and quality of life in women who undergo breast surgery: a qualitative study. BMC Womens Health 2009, 9:11. doi:1472-6874-9-11[pii]10.1186/1472-6874-9-11.

19. Ferrans CE, Powers M: Psychometric assessment of the Quality of Life Index. Res Nurs Health 1992, 15:29-38.

20. World Health Organization: International Classification of Impairments, Disabilities, and Handicaps: A manual of classification relating to the consequences of disease. Geneva: World Health Organization; 1980.

21. World Health Organization: International Classification of Functioning, Disability, and Health: ICF. Geneva: World Health Organization; 2001.

22. Valderas JM, Alonso J: Patient reported outcome measures: a modelbased classification system for research and clinical practice. Qual Life Res 2008, 17(9):1125-1135. doi:10.1007/s11136-008-9396-4.

23. Penckofer S, Ferrans CE, Fink N, Barrett ML, Holm K: Quality of life in women following coronary artery bypass graft surgery. Nurs Sci Q 2005, 18(2):176-183. doi:18/2/176[pii]10.1177/0894318405274832.

24. Sousa KH, Kwok OM: Putting Wilson and Cleary to the test: analysis of a HRQOL conceptual model using structural equation modeling. Qual Life Res 2006, 15(4):725-737. doi:10.1007/s111136-005-3975-4.

25. Baker SR, Pankhurst CL, Robinson PG: Testing relationships between clinical and non-clinical variables in xerostomia: a structural equation model of oral health-related quality of life. Qual Life Res 2007, 16(2):297-308. doi:10.1007/s11136-006-9108-x

26. Wettergren $L$, Bjorkholm M, Axdorph U, Langius-Eklof A: Determinants of health-related quality of life in long-term survivors of Hodgkin's lymphoma. Qual Life Res 2004, 13(8):1369-1379.

27. Mathias SD, Gao SK, Miller KL, Cella D, Snyder C, Turner R, et al: Impact of chronic Immune Thrombocytopenic Purpura (ITP) on health-related quality of life: a conceptual model starting with the patient perspective. Health Qual Life Outcomes 2008, 6:13. doi:1477-7525-6-13[pii]10.1186/14777525-6-13.

28. Cosby C, Holzemer WL, Henry SB, Portillo CJ: Hematological complications and quality of life in hospitalized AIDS patients. AIDS Patient Care STDS 2000, 14(5):269-279. doi:10.1089/108729100317731.

29. Frank A, Auslander GK, Weissgarten J: Quality of life of patients with endstage renal disease at various stages of the illness. Soc Work Health Care 2003, 38(2):1-27.

30. Hofer S, Benzer W, Alber H, Ruttmann E, Kopp M, Schussler G, et al: Determinants of health-related quality of life in coronary artery disease patients: a prospective study generating a structural equation model. Psychosomatics 2005, 46(3):212-223. doi:46/3/212[pii]10.1176/appi. psy.46.3.212

31. Janz NK, Janevic MR, Dodge JA, Fingerlin TE, Schork MA, Mosca $L$, et al: Factors influencing quality of life in older women with heart disease. Med Care 2001, 39(6):588-598.

32. Krethong $P$, Jirapaet $V$, Jitpanya $C$, Sloan $R$ : A causal model of healthrelated quality of life in Thai patients with heart-failure. J Nurs Scholarsh 2008, 40(3):254-260.

33. Mathisen $L$, Andersen MH, Veenstra M, Wahl AK, Hanestad BR, Fosse E: Quality of life can both influence and be an outcome of general health perceptions after heart surgery. Health Qual Life Outcomes 2007, 5:27. doi:1477-7525-5-27[pii]10.1186/1477-7525-5-27.

34. Orfila F, Ferrer M, Lamarca R, Tebe C, Domingo-Salvany A, Alonso J: Gender differences in health-related quality of life among the elderly: the role of objective functional capacity and chronic conditions. Soc Sci Med 2006, 63(9):2367-2380. doi:S0277-9536(06)00312-1 [pii]10.1016/j. socscimed.2006.06.017

35. Sousa KH: Description of a health-related quality of life conceptual model. Outcomes Manag Nurs Pract 1999, 3(2):78-82.

36. Vidrine DJ, Amick BC, Gritz ER, Arduino RC: Assessing a conceptual framework of health-related quality of life in a HIV/AIDS population. Qual Life Res 2005, 14(4):923-933.

37. Daggett $V$, Bakas $T$, Habermann B: A review of health-related quality of life in adult traumatic brain injury survivors in the context of combat veterans. J Neurosci Nurs 2009, 41(2):59-71.

38. Hill PD, Aldag JC, Hekel B, Riner G, Bloomfield P: Maternal Postpartum Quality of Life Questionnaire. J Nurs Meas 2006, 14(3):205-220.

39. Petchprapai $N$, Winkelman C: Mild traumatic brain injury: determinants and subsequent quality of life, A review of the literature. J Neurosci Nurs 2007, 39(5):260-272.

40. Fischer JS, LaRocca NG, Miller DM, Ritvo PG, Andrews H, Paty D: Recent developments in the assessment of quality of life in multiple sclerosis (MS). Mult Scler 1999, 5(4):251-259.

41. Hays RD, Bjorner JB, Revicki DA, Spritzer KL, Cella D: Development of physical and mental health summary scores from the patient-reported outcomes measurement information system (PROMIS) global items. Qual Life Res 2009, 18(7):873-880. doi:10.1007/s11136-009-9496-9.

42. Post MW, de Witte LP, Schrijvers AJ: Quality of life and the ICIDH: towards an integrated conceptual model for rehabilitation outcomes research. Clin Rehabil 1999, 13(1):5-15.

43. Cieza A, Stucki G: The International Classification of Functioning Disability and Health: It's development process and content validity. Eur J Phys Rehabil Med 2008, 44:303-313.

44. Miller ET, Murray L, Richards L, Zorowitz RD, Bakas T, Clark P, Billinger SA, American Heart Association Council on Cardiovascular Nursing and the Stroke Council: Comprehensive overview of nursing and interdisciplinary rehabilitation care of the stroke patient. A scientific statement from the American Heart Association. Stroke 2010, 41:2402-2448. doi:10.1161/ STR.0b013e3181e7512b.

doi:10.1186/1477-7525-10-134

Cite this article as: Bakas et al:: Systematic review of health-related quality of life models. Health and Quality of Life Outcomes 2012 10:134.

\section{Submit your next manuscript to BioMed Central and take full advantage of:}

- Convenient online submission

- Thorough peer review

- No space constraints or color figure charges

- Immediate publication on acceptance

- Inclusion in PubMed, CAS, Scopus and Google Scholar

- Research which is freely available for redistribution 